\title{
Advantages of visible-band spectral remote sensing at both satellite and near-surface scales for monitoring the seasonal dynamics of GPP in a Japanese larch forest
}

\author{
Reiko IDE*, $\dagger$, Tatsuro NAKAJI**, Takeshi MOTOHKA***, \\ and Hiroyuki OGUMA*

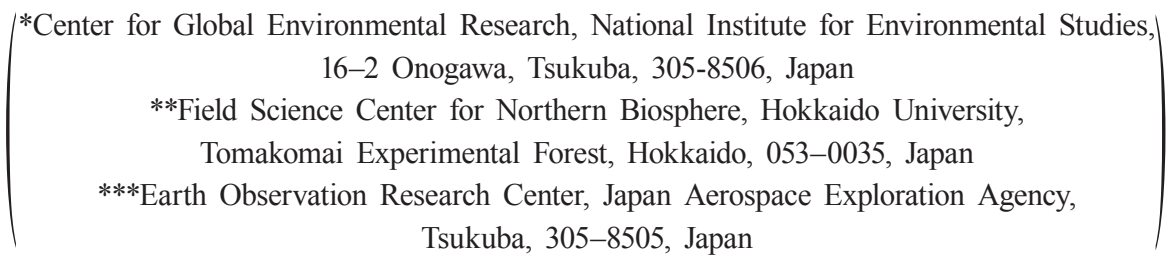

\begin{abstract}
Remotely sensed vegetation indices such as the normalized difference vegetation index (NDVI) or enhanced vegetation index (EVI) have been used to scale up flux-based gross primary production (GPP) measurements. Recently, the use of visible-band (VIS) indices for estimation of GPP has been proposed, and VIS_indices derived from digital cameras have been used for detecting phenological changes. To confirm the utility of remotely sensed VIS_indices for the evaluation of GPP in a Japanese larch forest, we investigated the relationships between flux-based GPP measurements and indices derived from both moderate resolution imaging spectroradiometer (MODIS) data and tower-mounted digital camera images. We evaluated the suitability of both traditional (NDVI and EVI) and VIS_indices (the greenred vegetation index (GRVI) and green ratio (GR)) at both satellite and near-surface scales for GPP estimation. We also used the MODIS data to evaluate the sensitivity of the indices to the effects of a severe forest disturbance. The results showed that VIS_indices had several advantages over the traditional indices: (1) seasonal variations in VIS_indices were more strongly correlated with GPP variations; (2) the vegetation growing season could be easily discriminated from the winter dormant period, because ground surface conditions affect VIS_indices less than they affect traditional indices; (3) the seasonal dynamics of vegetation could be determined at a satellite scale from MODIS data, and possibly even at a canopy scale from digital camera images; and (4) inter-annual variations of VIS_indices were likely to be more sensitive to vegetation changes after a disturbance. These results demonstrate the utility of VIS_indices for estimating GPP at satellite scales and possibly at the canopy scale. We suggest that multi-scale visible-band remote sensing could help our understanding of the ecosystem by improving the temporal and spatial resolutions of satellite data.
\end{abstract}

Key words: Digital camera, GPP, Green Ratio (GR), Green-Red Vegetation Index (GRVI), MODIS.

\section{Introduction}

Evaluation of carbon uptake and emissions by terrestrial ecosystems is necessary for predicting future

Received; January 5, 2011.

Accepted; March 18, 2011.

†Corresponding Author: ide.reiko@nies.go.jp climate change. Continuous tower-based eddy-covariance measurements of $\mathrm{CO}_{2}$ exchanges between the atmosphere and vegetation cover are carried out around the world (Reichstein et al., 2010), but to evaluate the global carbon balance, the tower-based $\mathrm{CO}_{2}$ flux data need to be scaled up to determine the spatial distribution of $\mathrm{CO}_{2}$ exchanges. For this purpose, remote 
Table 1. Vegetation indices used in this study. Here $\rho$ is reflectance for each wavelength range. MODIS suffixes: nir (near-infrared, 820-900 nm), red $(620-700 \mathrm{~nm})$, green $(500-570 \mathrm{~nm})$, and blue (450-480 nm). Digital numbers of each R, G, and B channel of camera images were used instead of reflectance.

\begin{tabular}{ll}
\hline Vegetation Index & Formulation \\
\hline NDVI (Normalized Difference Vegetation Index $)$ & $\left(\rho_{\text {nir }}-\rho_{\text {red }}\right) /\left(\rho_{\text {nir }}+\rho_{\text {red }}\right)$ \\
EVI (Enhanced Vegetation Index) & $2.5\left[\left(\rho_{\text {nir }}-\rho_{\text {red }}\right) /\left(\rho_{\text {nir }}+6 \rho_{\text {red }}-7.5 \rho_{\text {blue }}+1.0\right)\right]$ \\
GRVI (Green-Red Vegetation Index $)$ & $\left(\rho_{\text {green }}-\rho_{\text {red }}\right) /\left(\rho_{\text {green }}+\rho_{\text {red }}\right)$ \\
GR (Green Ratio) & $\rho_{\text {green }} /\left(\rho_{\text {red }}+\rho_{\text {green }}+\rho_{\text {blue }}\right)$ \\
\hline
\end{tabular}

sensing techniques are useful because they can be used for simultaneous wide-area observations.

The annual gross primary production (GPP) of terrestrial ecosystems is influenced by the plant growing period (i.e., plant phenology; Baldocchi et al., 2005; Richardson et al., 2010) and by disturbances, for example, typhoons, wildfires, or insect outbreaks (Ito, 2010; Sano et al., 2010). The phenological trajectory of vegetation must be assessed for the accurate estimation of annual and interannual variations of GPP. Satellite and ground-based remote sensing techniques are also useful for the detection of such phenological changes and disturbances because they are suitable for repetitive observations.

Vegetation indices such as NDVI or EVI (Table 1) derived from satellite remote sensing data have been used to estimate GPP at regional and continental scales (e.g., Tucker, 1979; Xiao et al., 2004a; Zhao et al., 2005) and to detect vegetation phenological timings (Zhou et al., 2001; Zhang et al., 2003; Fisher and Mustard, 2007). However, inconsistencies between MODIS-derived NDVI or EVI results and vegetation phenology or flux-based GPP data derived from ground observations have been reported (Xiao et al., 2004b; Gitelson et al., 2006; Jenkins et al., 2007; Nagai et al., 2010). As an alternative, recent studies have suggested that newly developed visible-band (VIS) vegetation indices: the MODIS-derived greenery ratio (GR) data have been used for effective estimation of GPP in a rice paddy (Harazono et al., 2009), and the green-red vegetation index (GRVI) results derived from ground observations have been utilized to detect phenological changes in several types of ecosystems (Motohka et al., 2010).

VIS_indices can be also derived from the colors in digital camera images. Commercially available digital cameras are inexpensive and convenient to use as near-surface remote sensors, so monitoring camera networks have recently been established and are now widely used to detect vegetation phenology: the Phenological Eyes Network (PEN; Nishida, 2007) in Japan, and the USA National Phenology Network (http://www.usanpn.org/). Camera-based VIS_indices such as the green excess index (Richardson et al., 2007; Graham et al., 2010; Ide and Oguma, 2010), and the green ratio (Ahrends et al., 2008; Maeda et al., 2008) have recently been used for the effective detection of phenological timings. The close relationship between seasonal variations in camera-based VIS_indices values and those in flux-based GPP measurements has also been examined (Ahrends et al., 2009; Richardson et al., 2009; Graham et al., 2010).

Therefore, we hypothesized that VIS_indices can sensitively show seasonal variations in plant pigments, and thus are useful for evaluating GPP. Only a few studies have applied VIS_indices to GPP estimation at either satellite or near-surface scales. The objective of this present study was to determine the utility of remotely sensed VIS_indices for the evaluation of GPP in a deciduous needleleaf forest at both satellite and near-surface scales. We investigated the relationships between flux-based GPP and several indices, including traditional indices (NDVI and EVI) and VIS_indices (GRVI and GR) derived from both MODIS data and digital camera images. Furthermore, we examined seasonal and interannual variations in the MODIS indices for 9 years both before and after a disturbance to ascertain how well VIS_indices could detect changes to an ecosystem caused by a disturbance.

\section{Methods}

\subsection{Study site}

The study site was the Tomakomai Flux Research Site $\left(42^{\circ} 44^{\prime} \mathrm{N}, 141^{\circ} 31^{\prime} \mathrm{E}, 125 \mathrm{~m}\right.$ above sea level), which is in a temperate deciduous coniferous forest area of northern Japan. About $81 \%$ of the approximately 


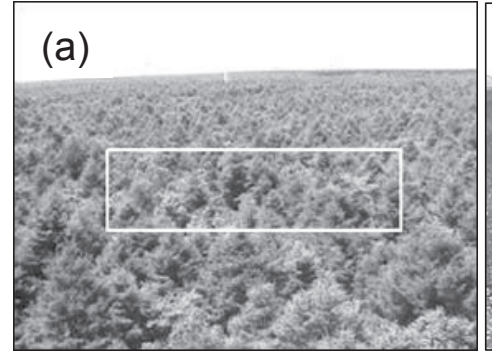

\section{(b)}

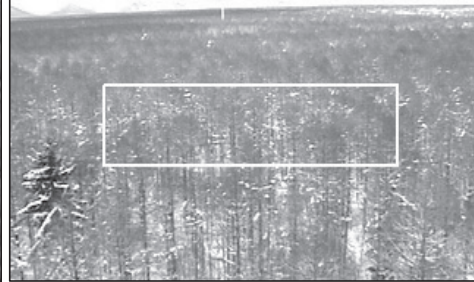

(c)

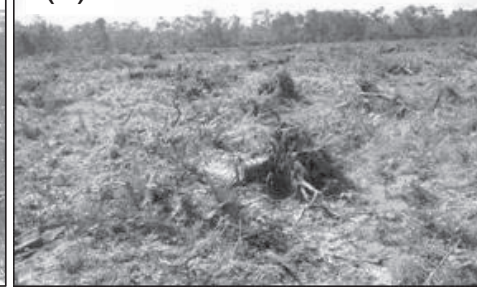

Fig. 1. Tomakomai flux research site. (a) Former larch forest in summer. The rectangle encloses the selected area of interest (AOI) representing the larch canopy for obtaining the VIS_indices. (b) The same but in winter. (c) After the forest destruction. The area became grassland with scattered uprooted larch stumps, in 2005.

100-ha site was originally dominated by a stand of Japanese larch (Larix kaempferi). In 2003, these trees were about 45 years old, $15 \mathrm{~m}$ tall, and with a mean diameter at breast height of $19 \mathrm{~cm}$. Other trees on the site included deciduous trees such as birch (Betula ermanii, B. platyphylla) and Japanese elm (Ulmus japonica) mixed with evergreen coniferous species such as spruce (Picea jezoensis). The forest floor was thickly covered with Japanese spurge (Pachysandra terminalis), ferns (Dryopteris crassirhizoma), and other understory species. During 2001-2003 the mean air temperature was $6.2^{\circ} \mathrm{C}$ and the mean annual precipitation was $1043 \mathrm{~mm}$.

The flux tower and the forest at the site were completely destroyed by typhoon Songda on 8 September 2004. More than $90 \%$ of the trees were uprooted and blown down by extreme winds, forcing all observations at this site to cease. After the typhoon, most of the dead trees were removed from the site. As a result, the vegetation drastically changed from being a larch forest to being grassland dominated by red raspberry (Rubus idaeus) (Fig. 1). Before the typhoon, the annual maximum aboveground biomass was $91.8 \mathrm{Mg} \mathrm{ha}^{-1}$, but in 2006 this had decreased to $2.7 \mathrm{Mg} \mathrm{ha}^{-1}$ (3\%). It then recovered to $4.0 \mathrm{Mg} \mathrm{ha}^{-1}$ by 2007 (Sano et al., 2010). The annual maximum leaf area index (LAI), which was $9.4 \mathrm{~m}^{2} \mathrm{~m}^{-2}$ before the typhoon (Hirata et al., 2007), was $3.7 \mathrm{~m}^{2} \mathrm{~m}^{-2}$ (39\%) in 2006 and $3.9 \mathrm{~m}^{2}$ $\mathrm{m}^{-2}$ in 2007.

\subsection{Measurement of $\mathrm{CO}_{2}$ flux and micrometeoro- logical parameters}

From January 2001 to August 2004, the $\mathrm{CO}_{2}$ flux $\left(F_{\mathrm{c}}\right)$ was measured continuously using the eddy covariance technique with a closed-path infrared gas analyzer (Li6262; Li-Cor, Lincoln, Nebraska, USA), and meteorological parameters were simultaneously measured at a $27 \mathrm{~m}$ height on the tower (Hirano et al., 2003). The net ecosystem exchange (NEE) was calculated as the sum of $F_{\mathrm{c}}$ and the rate of change in $\mathrm{CO}_{2}$ storage below the $F_{\mathrm{c}}$ measurement height.

The observed NEE was gap-filled and partitioned into ecosystem respiration (RE) and GPP (Falge et al., 2001). RE was estimated by regression using the equation of Lloyd and Taylor (1994) based on the soil temperature and nighttime NEE under stable conditions (friction velocity $\left(u^{*}\right)>0.3 \mathrm{~m} \mathrm{~s}^{-1}$ ). Half-hourly GPP $\left(\mu \mathrm{mol} \mathrm{CO}_{2} \mathrm{~m}^{-2} \mathrm{~s}^{-1}\right)$ was approximated with a 7-day moving window as a function of photosynthetically active radiation ( $\mu \mathrm{mol}$ photon $\mathrm{m}^{-2} \mathrm{~s}^{-1}$ ) using the non-rectangular hyperbolic light-response equation (Thornley, 1976), and summed as daily GPP (gC $\left.\mathrm{m}^{-2} \mathrm{~d}^{-1}\right)$.

\subsection{Spectral reflectance and indices}

We analyzed the relationships between photosynthetic parameters and several indices (Table 1). NDVI and EVI are indices of the green leaf quantity based on differences in reflectance between red and near-infrared (NIR) bands. Chlorophyll has high absorbance in the visible red wavelength region, whereas there is strong reflectance from plant cell walls and intracellular water in the NIR region. Thus, an increase in the quantity of healthy green leaves is accompanied by a decrease in red reflectance and a rise in NIR reflectance.

NDVI is widely used for assessing parameters such as the vegetation cover ratio, LAI, and the fraction of absorbed photosynthetically active radiation (e.g., Sellers et al., 1992; Myneni et al., 1997), and vegetation phenology. However, it has the disadvantage of saturating at a high biomass (Goward and Huemmrich, 1992). EVI was proposed to overcome this problem and to mitigate the effects of aerosols and soil by the incorporation of blue wavelength reflectance (Huete 
et al., 2002).

In addition to these indices calculated by the combination of VIS and NIR bands, we evaluated two VIS_indices: GRVI and GR. GRVI is calculated as the normalized difference between the visible green and red bands (Table 1). As green leaves develop, the reflectance of visible green increases and that of red decreases. In contrast, at the time of leaf senescence, the reflectance of green decreases and that of red increases. In accordance with this definition, GRVI $>$ 0 indicates green vegetation, GRVI $<0$ indicates soil, leaves that have changed color in autumn or leafless trees, and GRVI $\approx 0$ indicates water or snow. Thus, GRVI is useful for assessing crown closure and crown bulk density (Falkowski et al., 2005). Moreover, it is a phenological indicator in that it is sensitive to green-up, and even senescence, which is difficult to detect with NDVI (Motohka et al., 2010). GR is defined as the ratio of green to the total digital numbers $(\mathrm{R}+\mathrm{G}+\mathrm{B})$ of camera images (Table 1), and it can effectively detect phenological events (Ahrends et al., 2008; Maeda et al., 2008). Similarly, GR is used as the green reflectance ratio to total visible reflectance of MODIS data to estimate GPP (Harazono et al., 2009). According to the definition, $G R \approx 1 / 3$ indicates white or black targets such as snow, ice or soil. In addition, another camera-based phenological index was defined as the green excess index $(2 \mathrm{G}-\mathrm{RBi}=2 \mathrm{G}-(\mathrm{R}+$ B); Richardson et al., 2007), and applied on various types of vegetation to determine phenological timings (Graham et al., 2010). However, each channel value shows large variations depending on the intensity of the incident solar radiation. In order to minimize these variations, each channel value needs to be normalized relative to the instantaneous total brightness $(\mathrm{R}+\mathrm{G}+\mathrm{B})$. When $2 \mathrm{G}-\mathrm{RBi}$ is calculated from the normalized ratio of each channel values instead of the digital numbers, $2 \mathrm{G}-\mathrm{RBi}$ indicates almost the same as GR with the transformed formulation $2 \mathrm{G}-\mathrm{RBi}=3 \mathrm{GR}-1$.

\subsubsection{Satellite data}

We downloaded 8-day composite surface reflectance Terra/MODIS data (MOD09A1, collection 5) from the Land Processes Distributed Active Archive Center (LP DAAC; https://lpdaac.usgs.gov/). MOD09A1 data are atmospherically corrected products. We used the 500-m-resolution data of band 1 (red, 620-700 nm), band 2 (NIR, 820-900 $\mathrm{nm}$ ), band 3 (blue, 450-480 $\mathrm{nm}$ ), and band 4 (green, $500-570 \mathrm{~nm}$ ) from 2001 to 2009. We extracted 3 pixels of MODIS data covering the Tomakomai flux site, and excluded poor quality data with cloud contamination by using the MOD09 state flag.

\subsubsection{Analysis of digital camera images}

We observed the phenological changes of the larch canopy with a digital camera (Fieldeye FC13, Yokogawa Electric Corporation, Tokyo, Japan) from 2001 to 2004. The camera was mounted on the flux tower and rotated about once an hour, taking fixed-view photographs in 15 directions. About 3.3 years of digital images were archived in jpeg format at a resolution of $640 \times 480$ pixels. The resolution was low because the original purpose of the camera was for surveillance. To avoid the influence of varying solar angles, only daily images taken at around noon were used. We used the photographic images to visually determine the phenological timing of snowmelt, larch budburst, canopy green-up, autumn leaf color changes, and leaf fall. Here, we defined the growing period as the period from the end of the snow-covered period in spring until all leaves had fallen in autumn.

We selected an area of interest (AOI) captured in the images to represent the larch forest canopy (Fig. 1), and developed semi-automatic algorithms for image analysis using free software (ZeGraph v. 2.4; http://www.zegraph.com/). First, digital numbers (pixel values) of each channel (R, G, and $B$ ) were extracted and averaged within each $\mathrm{AOI}$ image at daily intervals; data obtained under rainy or foggy weather conditions were excluded. Then, GRVI and GR were calculated from the averaged digital numbers (Table 1).

The VIS indices were calculated from MODIS data using spectral reflectance data and from camera data using the R, G, and B digital numbers (instead of reflectance).

\section{Results}

\subsection{Seasonal variations in GPP and MODIS in- dices}

The seasonal variations of GPP corresponded to the vegetation phenology (Fig. 2). GPP began to increase and the growing period started in late April, after the snow had melted, and GPP then increased rapidly for about 3 weeks after the budburst of larch. Larch shoots elongated from mid-June to July, and GPP remained high during the summer, with large daily fluctuations that depended on the amount of solar radiation. Maximum values were reached at the beginning of July (day of year: DOY $\approx 180$ ), and gradually decreased in 


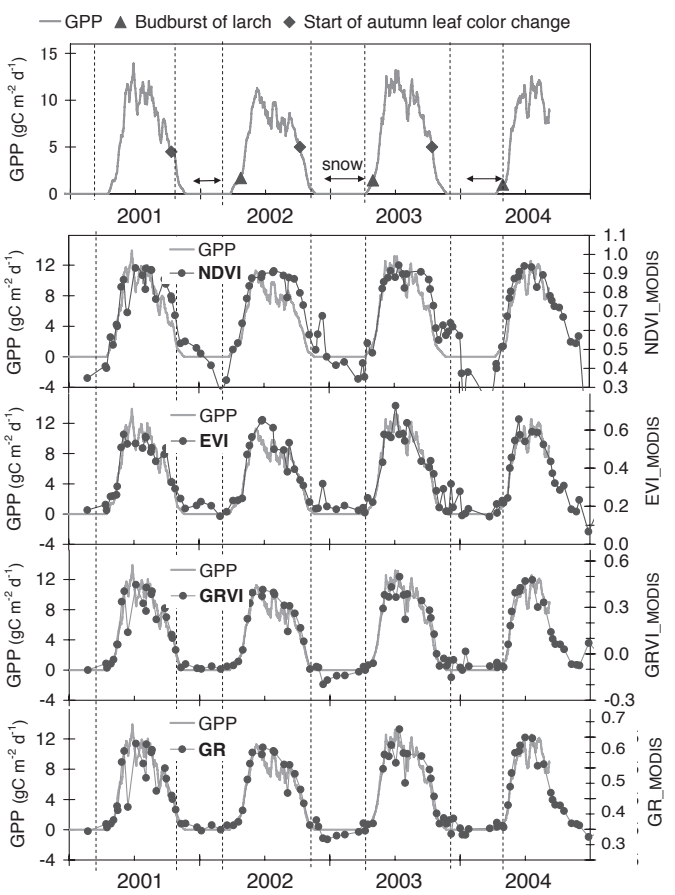

Fig. 2. Seasonal dynamics of daily GPP (left axis) and of MODIS-derived NDVI, EVI, GRVI, and GR (right axis). Vertical dashed lines denote the start and end of each growing period, and arrows indicate snow covered periods.

late summer, even though the temperature and the LAI remained at their maximum levels. GPP continued to decrease as the leaves changed to their autumn colors, and fell to 0 after the larch leaf fall in mid-November (DOY $\approx 315$ ).

We compared the seasonal dynamics of each vegatation index with that of GPP (Fig. 2). NDVI showed wide, bell-shaped seasonal patterns with a long saturated period during the summer, and clearly started to decrease later than GPP. The patterns of EVI, GRVI and GR, in contrast, were sharper and asymmetrical, with earlier declines. NDVI increased abruptly from their minimum level when the snow disappeared in spring, and then increased again after the larch leaf flush. The seasonal patterns of EVI and GPP agreed better than NDVI and GPP, however they differed sometimes especially at leaf fall periods. The seasonal patterns of GRVI and GR were similar. Both increased linearly for 1 month just after budburst, and they gradually decreased after reaching a midsummer maximum, similar to GPP.
Table 2. Correlation coefficients ( $r$ ) of seasonal variations between GPP and indices derived from MODIS data and camera images during the growing period under clear sky conditions.

\begin{tabular}{lcc}
\hline Sensor & MODIS $(\mathrm{n}=61)$ & Camera $(\mathrm{n}=212)$ \\
\hline NDVI & 0.91 & \\
EVI & 0.92 & \\
GRVI & 0.95 & 0.88 \\
GR & 0.93 & 0.85 \\
\hline
\end{tabular}

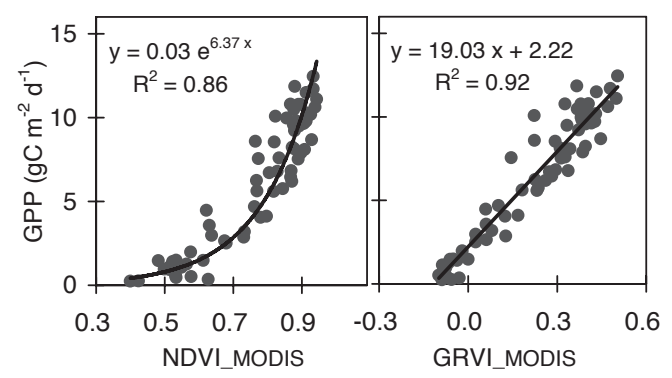

Fig. 3. Relationships between daily GPP and MODIS-based NDVI (a) and GRVI (b) during the growing period (GPP $>0$ ) from January 2001 to August 2004.

GPP and each VI were significantly correlated (Table $2 ; n=61, p<0.0001)$. Although NDVI was strongly correlated with GPP $(r=0.91)$, the relationship was exponential (Fig. 3a) because of NDVI saturation during summer. In addition, the start of the autumn decrease of NDVI was later than that of GPP.

Seasonal variations of GPP and both VIS_indices (GRVI and GR) agreed better across all seasons ( $r=0.95$ and 0.93 , respectively) than the traditional indices. GRVI showed the strongest linear correlation with GPP among the four indices $\left(\mathrm{R}^{2}=0.92\right)$ during the growing periods of 3.5 years (Fig. 3b). GPP was empirically related to GRVI under clear sky conditions as follows:

$$
\mathrm{GPP}=19.03 \mathrm{GRVI} \_ \text {MODIS }+2.22 \quad(\text { Eq. } 1)
$$

At this site, GRVI ranged from -0.1 to 0.5 for GPP $>0$.

\subsection{Camera-based indices}

Camera-based GRVI and GR of the larch canopy (Fig. 1) showed seasonal variations (Fig. 4). The indices increased after larch budburst and reached their maximum values at around $\mathrm{DOY}=150$, this 


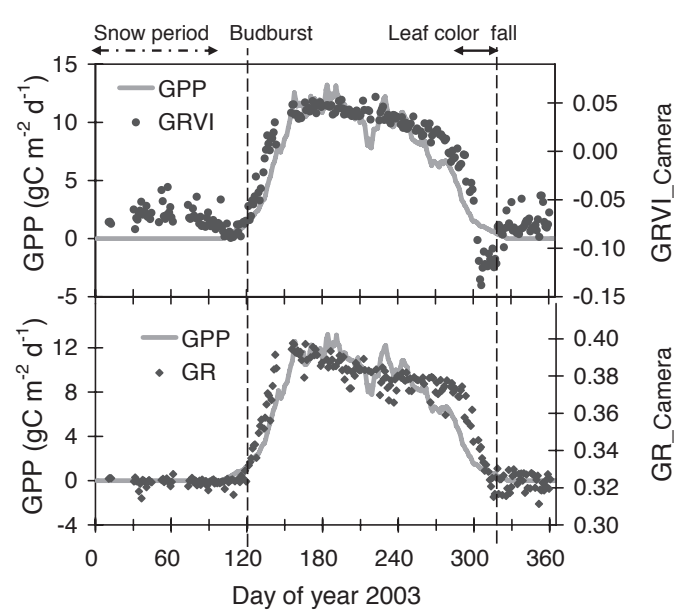

Fig. 4. Seasonal variations in GPP and in camerabased GRVI and GR in 2003. Data from rainy or foggy days were excluded. Vertical dashed lines indicate the budburst and complete leaf fall in larch. Dashedarrow denotes snow-covered period and solid arrow denotes autumn leaf color period.

preceded an increase of GPP. As the leaves started their autumn color change, at around DOY $=286$, both indices strongly declined, beginning their decrease later than the GPP. GRVI exhibited a pronounced negative spike at the time of the maximum autumn leaf color $(\mathrm{DOY}=306)$. In winter, after the complete leaf fall $(\mathrm{DOY}=313)$, GRVI values were noisy, with day-to-day variations ranging from -0.04 to -0.09 , reflecting the mixture of leafless trees, soil, and snow (Fig. 1b). The day-to-day variations of GR values during the dormant period were smaller.

Thus the seasonal variations of the camera-based GRVI and GR captured the phenology of the larch trees and were similar to the seasonal GPP variations. Camera-based GRVI and GR were strongly and significantly correlated with GPP $(n=212, r=0.88$ and 0.85 , respectively, $p<0.0001$ ) during the growing periods of 3.3 years (Table 2). Although the absolute values of camera-based indices were different from those of the MODIS-derived indices, their seasonal patterns were similar.

\subsection{Seasonal trend of indices before and after the disturbance}

We obtained a time series of the MODIS indices covering 9 years, both before and after the disturbance (Fig. 5). Seasonal variations of all indices changed drastically just after the typhoon struck in September

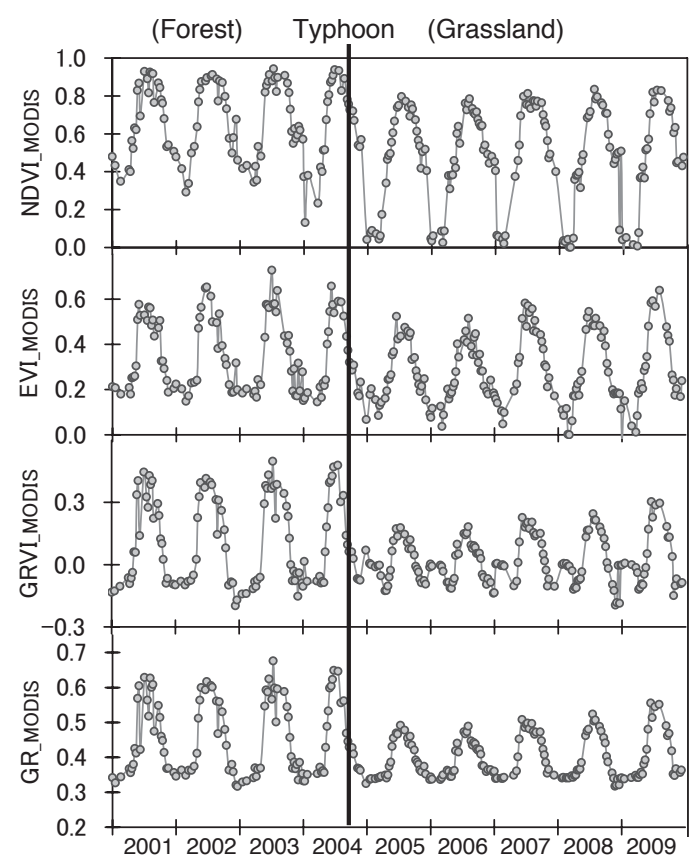

Fig. 5. Seasonal variations of satellite-based NDVI, EVI, GRVI, and GR before and after the disturbance.

2004. The maximum (June to August) GRVI and GR values in 2006 decreased to $33 \%$ and $49 \%$, respectively, of their averaged maximum values over 2001-2004, whereas the maximum NDVI and EVI values decreased to $81 \%$ and $74 \%$, respectively, of their 2001-2004 averages. The maximum GRVI and GR values recovered year-by-year, reaching $71 \%$ and $79 \%$, respectively, of their 2001-2004 averages in 2009. In contrast after the disturbance aboveground biomass and LAI decreased to $3 \%$ and $39 \%$, respectively (See 2.1; Sano et al., 2010).

The yearly minimum values of NDVI and EVI during the snow-covered period changed greatly, from about 0.3 to nearly 0 and from 0.2 to 0 , respectively. In contrast, the minimum GRVI values during the snow-covered period increased a little, from -0.1 to 0 , whereas those of GR were similar both before and after the disturbance.

\section{Discussion}

\subsection{Advantages of visible-bands indices}

We identified the advantages of using VIS_indices (GRVI and GR) for evaluating GPP. First, the seasonal variations in MODIS VIS_indices showed strong linear 
correlations with those in GPP, indicating agreement of both seasonal and interannual variations. The results supported a strong correlation between photosynthetic parameters and GR reported by Harazono et al. (2009). VIS_indices are sensitive to green leaf color, so they responded to photosynthetic pigments. The large decrease in the ratio after the forest disturbance and the subsequent yearly increase in both GRVI and GR indicate that the VIS_indices can respond sensitively to the changes in leaf color or leaf density. Falkowski et al. (2005) and Motohka et al. (2010) reported similar findings for GRVI, and Ide and Oguma (2010) for 2G-RBi ( $\approx \mathrm{GR})$ derived from camera images.

On the other hand, NDVI was exponentially related to GPP. A much higher reflectance in the NIR range from vegetation than in the red range means that NDVI and EVI sensitively reflect the amount of biomass affected by NIR reflectance. As a result, NDVI and EVI responded even to fallen leaves and defoliated trees, and thus overestimated GPP even after the growing season. The grassland and debris after the typhoon disaster (Fig. 1c) also probably led to overestimations. Climate change is expected to augment the frequency and magnitude of cyclones, typhoons, and other natural disasters in the future (IPCC, 2007), so evaluation of the effects of disturbances is important for ecosystem modeling. We plan to continue to investigate the post-disturbance relationships between indices and GPP in this forest.

Another advantage of the MODIS VIS_indices is that they were less affected by ground surface conditions than NDVI or EVI. The minimum NDVI value before the forest destruction was around 0.4 because of defoliated tree trunks and branches (Fig. 1b), whereas after the destruction of the forest, it drastically declined (to nearly 0), reflecting the snow-covered grassland. Furthermore, the minimum range of NDVI for green leaves differs from site to site (Motohka et al., 2010), and EVI also varies depending on the ground conditions during winter.

In contrast, the minimum GRVI and GR values changed little after the collapse. Theoretically, GRVI= 0 and $\mathrm{GR}=1 / 3$ for snow, ice, water, and $\mathrm{GR} \approx 1 / 3$ for soil and defoliated trees as well. Therefore, the stable minimum values of GR can be used to distinguish the vegetation growing period from the dormant period.

\subsection{Multi-scale remote sensing using VIS_indi- ces}

Another advantage of VIS_indices is that analysis of digital camera images can be used along with satellite data. In this study, we assessed the GPP and phenology of the larch forest using two different temporal and spatial scales. The MODIS data acquired with a nadir view angle covered a wide area of $500 \mathrm{~m} \times 500 \mathrm{~m} \times 3$ pixels that included both the 200-m measured GPP footprint (Hirata et al., 2007) and trees other than larch, whereas the AOI in the camera image acquired with an off-nadir view angle from the flux tower included only a small area of larch canopy. The camera-based indices tended to overestimate the greenness in early and late summer, probably because the camera viewed the forest canopy from the side, so less ground was included than in the MODIS image. In addition to the differences in scale, target, and view angle, the spectral sensitivity and wavelength range of each $\mathrm{R}, \mathrm{G}$, and $\mathrm{B}$ channel differed between the camera and MODIS. In addition, the sensors in an inexpensive camera are calibrated less than satellite sensors. Moreover, the MODIS indices were calculated from reflectance data, and the camera indices were calculated from brightness data. Therefore, the absolute values of the indices at the two scales were different.

Despite these differences, only the camera-based GRVI and GR captured the detailed seasonal dynamics of the larch canopy, such as the prominent negative GRVI spike in autumn and the peaks of GRVI and GR in spring, sensitively indicating maximum leaf color in autumn and complete leaf expansion in spring. Ahrends et al. (2009) explained similar spring maximum values of GR as indicating complete leaf expansion and reported that the values decreased when overlapping leaves caused the canopy to appear darker green. Motohka et al. (2010) found a similar autumn spike and spring peak in daily GRVI data derived from canopy-scale hemispherical spectroradiometer data. However, both the negative spike and the spring peak were smoothed in the MODIS indices, because of their coarse temporal and spatial resolution. Thus, camera-based indices can provide useful phenological information at the species scale.

However, the best way to utilize camera-based nearsurface remote sensing in conjunction with satellite data remains to be determined. Previously, Maeda et al. (2008) and Graham et al. (2010) showed the advantage of camera-based GR over MODIS NDVI or EVI for detecting phenology, because of its fine temporal resolution. However, camera image analysis is a recent development, and that few studies of 
MODIS VIS_indices have been conducted to date. The possibility of utilizing VIS_indices at both satellite and ground (camera) scales has been discussed for the first time in this present study.

Overall, we found good agreement in seasonal dynamics between the camera-based indices and GPP, because this study site was a nearly homogeneous larch forest and even a small AOI could well represent the larch forest. Previous studies showed that cameraderived indices can successfully detect phenological changes at the species scale (Richardson et al., 2007; Ahrends et al., 2008; Ide and Oguma, 2010). Therefore, digital images might be useful for estimating GPP at fine spatial (i.e., community, canopy, species, or individual scales) and temporal resolutions, such as daily time steps, which are below the limits of detection by satellite remote sensing. GPP values measured at a flux tower integrate the various seasonal variations of different species. By using VIS_indices at the species scale, the contribution of each species to the GPP could be analyzed, or indices of heterogeneous pixels (mixed forest) could be decomposed to determine the contribution of each end-member (each species). Furthermore, it should be possible to estimate GPP over a wide area by integrating the indices of each component, weighted according to its distribution ratio. In addition, camera-based indices could be used for ground-truthing of MODIS indices and GPP to correct outliers, or for gap filling of missing values. Thus, we suggest that digital images can supplement satellite data and also be used to downscale heterogeneous pixel data from satellites.

A digital camera is an inexpensive, easy to operate, and convenient near-surface remote sensor. If many digital cameras were mounted to cover wide areas following a standardized protocol, multi-scale remote sensing could supplement satellite data to improve global carbon exchange estimation and enhance our understanding of ecosystems.

\section{Conclusions}

The remotely sensed VIS_indices GRVI and GR were obtained at both a satellite scale and a near-surface scale from MODIS data and digital camera images. We demonstrated that VIS_indices have several advantages over traditional indices (NDVI and EVI): (1) the seasonal variations in MODIS GRVI and GR were more strongly correlated with flux-based GPP variations; (2) the vegetation growth period was easily discriminated from the winter dormant period by MODIS GRVI and GR, which were less influenced by ground surface conditions; (3) seasonal patterns in canopy-scale GRVI and GR derived from digital camera images also agreed well with GPP seasonality; and (4) the seasonal variations of VIS_indices seemed to be more sensitive to vegetation changes after the disturbance. We demonstrated the application of the VIS_indices to the estimation of GPP under clear sky conditions. We plan to further investigate the responses of GRVI and GR to forest disturbances. We suggest that multi-scale visible-band remote sensing can improve the temporal and spatial resolution of satellite data.

\section{Acknowledgments}

ZeGraph (http://www.zegraph.com/) was used for the non-linear regression calculations and for image analysis. We deeply appreciate the guidance and cooperation provided by Jiye Zeng. Financial support was provided by Ministry of Environment (No. D-0909).

\section{References}

Ahrends, H. E., Brügger, R., Stöckli, R., Schenk, J., Michna, P., Jeanneret, F., Wanner, H., and Eugster, W., 2008: Quantitative phenological observations of mixed beech forest in northern Switzerland with digital photography. J. Geophys. Res., 113, G04004, doi:10.1029/2007JG000650.

Ahrends, H. E., Etzold, S., Kutsch, W. L., Stöckli, R., Brügger, R., Jeanneret, F., Wanner, H., Buchmann, N., and Eugster, W., 2009: Tree phenology and carbon dioxide fluxes: use of digital photography for process-based interpretation at the ecosystem scale. Clim. Res., 39, 261-274.

Baldocchi, D. D., Black, T. A., Curtis, P. S., Falge, E., Fuentes, J. D., Granier, A., Gu, L., Knohl, A., Pilegaard, K., Schmid, H. P., Valentini, R., Wilson, K., Wofsy, S., Xu, L., and Yamamoto, S., 2005: Predicting the onset of net carbon uptake by deciduous forests with soil temperature and climate data: a synthesis of FLUXNET data. Int. J. Biometeorol., 49, 377-387.

Falge, E., Baldocchi, D. D., Olson, R., Anthoni, P., Aubinet, M., Bernhofer, C., Burba, G., Ceulemans, R., Clement, R., Dolman, H., Granier, A., Gross, P., Grunwald, T., Hollinger, D., Jensen, N. O., Katul, G., Keronen, P., Kowalski, A., Lai, C. T., Law, B. E., Meyers, T., Moncrieff, H., Moors, E., Munger, J. W., 
Pilegaard, K., Rannik, U., Rebmann, C., Suyker, A., Tenhunen, J., Tu, K., Verma, S., Vesala, T., Wilson, K., and Wofsy, S., 2001: Gap filling strategies for defensible annual sums of net ecosystem exchange. Agric. For. Meteorol., 107, 43-69.

Falkowski, M., Gressler, P. E., Morgan, P., Hudak, A. T., and Smith, A. M. S., 2005: Characterizing and mapping forest fire fuels using ASTER imagery and gradient modeling. Forest Ecol. Manage., 217, 129-146.

Fisher, J., and Mustard, J. F., 2007: Cross-scalar satellite phenology from ground, Landsat, and MODIS data. Remote Sens. Environ., 109, 261-273.

Gitelson, A. A., Vina, A., Verma, S. B., Rundquist, D. C., Arkebauer, T. J., Burba, G. G., and Suyker, A. E., 2006: Relationship between gross primary production and chlorophyll content in crops: Implication for the synoptic monitoring of vegetation productivity. J. Geophys. Res., 111, D08A11, doi:10.1029/2005JD006017.

Goward, S. N., and Huemmrich, K. F., 1992: Vegetation canopy PAR absorptance and the Normalized Difference Vegetation Index: An assesement using the SAIL model. Remote Sens. Environ., 39, 119-140.

Graham, E. A., Riordan, E. C., Yuen, E. M., Estrin, D., and Rundel, P., 2010: Public Internet-connected cameras used as a cross-continental ground-based plant phenology monitoring system. Global Change Biol., 16, 3014-3023.

Harazono, Y., Chikamoto, K., Kikkawa, S., Iwata, T., Nishida, N., Ueyama, M., Kitaya, Y., Mano, M., and Miyata, A., 2009: Applications of MODIS-visible bands index, greenery ratio to estimate $\mathrm{CO} 2$ budget of a rice paddy in Japan. J. Agric. Meteorol., 65, 365-374.

Hirano, T., Hirata, R., Fujinuma, Y., Saigusa, N., Yamamoto, S., Harazono, Y., Takada, M., Inukai, K., and Inoue, G., 2003: $\mathrm{CO}_{2}$ and water vapor exchange of a larch forest in northern Japan. Tellus, 55B, 244-257.

Hirata, R., Hirano, T., Saigusa, N., Fujinuma, Y., Inukai, K., Kitamori, Y., and Yamamoto, S., 2007: Seasonal and interannual variations in carbon dioxide exchange of a temperate larch forest. Agric. For. Meteorol., 147, 110-124.

Huete, A., Didan, K., Miura, T., Rodriguez, E. P., Gao, X., and Ferreira, L. G., 2002: Overview of the radiometric and biophysical performance of the MODIS vegetation indices. Remote Sens. Environ.,
83, 195-213.

Ide, R., and Oguma, H., 2010: Use of digital camera for phenological observations. Ecol., Informatics., 5, 339-347.

Intergovernmental Panel on Climate Change, 2007: Climate change 2007-the physical science basis: contribution of working group I to the fourth assessment report of the IPCC. Cambridge University Press, London.

Ito, A., 2010: Evaluation of the impacts of defoliation by tropical cyclones on a Japanese forest's carbon budget using flux data and a process-based model. J. Geophys. Res., 115, G04013, doi:10.1029/2010JG001314.

Jenkins, J. P., Richardson, A. D., Braswell, B. H., Ollinger, S. V., Hollinger, D. Y., and Smith, M-L., 2007: Refining light-use efficiency calculations for a deciduous forest canopy using simultaneous towerbased carbon flux and radiometric measurements. Agric. For. Meteorol., 143, 64-79.

Lloyd, J., and Taylor, J. A., 1994: On the temperature dependence of soil respiration. Funct. Ecol., 8, 315-323.

Maeda, T., Gamo, M., Kondo, H., Panuthai, S., Ishida, A., Nagai, S., and Okamoto, S., 2008: Leaf phenology detected by fixed view camera images in a tropical seasonal forest at Mae Klong, Thailand. In Tropical forestry change in a changing world Vol. 3. FORTROP II International Conference, Kasetsart University, Bangkok, Thailand, pp. 167-181.

Motohka, T., Nasahara, K., Oguma, H., and Tsuchida, S., 2010: Applicability of green-red vegetation index for remote sensing of vegetation phenology. Remote Sens., 2, 2369-2387.

Myneni, R. B., Nemani R. R., and Running, S. W., 1997: Estimation of global leaf area index and absorbed PAR using radiative transfer models. IEEE Trans. Geosci. Remote Sens., 35 (6), 1380-1393.

Nagai, S., Saigusa, N., Muraoka, H., and Nasahara, N. K., 2010: What makes the satellite-based EVI-GPP relationship unclear in a deciduous broad-leaved forest? Eco. Res., 25, 359-365.

Nishida, K., 2007: Phenological Eyes Network (PEN) --- A validation network for remote sensing of the terrestrial ecosystems. Asiaflux Newsletter, 21, 9-13.

Reichstein, M., Jung, M., Carvalhais, N., Mahecha, M., Beer, C., and Tomelleri, E., 2010: FLUXNET-From Point to Globe. Fluxletter, 3, 4-8.

Richardson, A. D., Jenkins, J. P., Braswell, B. H., 
Hollinger, D. Y., Ollinger, S. V., and Smith, M-L., 2007: Use of digital webcam images to track spring green-up in a deciduous broadleaf forest. Oecologia, 152, 323-334.

Richardson, A. D., Braswell, B. H., Hollinger, D. Y., Jenkins, J. P., and Ollinger, S. V., 2009: Near-surface remote sensing of spatial and temporal variation in canopy phenology. Ecol. Applic., 19, 1417-1428.

Richardson, A. D., Black, T. A., Ciais, P., Delbart, N., Friedl, M., Gobron, N., Hollinger, D. Y., Kutsch, W. L., Longdoz, B., Luyssaert, S., Migliavacca, M., Montagnani, L., Munger, J. W., Moors, E., Piao, S., Rebmann, C., Reichstein, R., Saigusa, N., Tomelleri, E., Vargas, R., and Varlagin, A., 2010: Influence of spring and autumn phenological transition on forest ecosystem productivity. Phil. Trans. R. Soc., 365, 3227-3246.

Sano, T., Hirano, T., Liang, N., and Fujinuma, Y., 2010: Carbon dioxide exchange of a larch forest after a typhoon disturbance. Forest Ecol. Manage., 260, 2214-2223.

Sellers, P. J., Berry, J. A., Collatz, G. J., Field, C. B., and Hall, F. G., 1992: Canopy reflectance, photosynthesis, and transpiration: 3. A reanalysis using improved leaf models and a new canopy integration scheme. Remote Sens. Environ., 42 (3), 187-216.

Thornley, J. H. M., 1976: Mathematical Models in Plant Physiology. Academic Press, London, 318 pp.
Tucker, C. J., 1979: Red and photographic infrared linear combinations for monitoring vegetation. Remote Sens. Environ., 8, 127-150.

Xiao, X. M., Zhang, Q. Y., Braswell, B. H., Urbanski, S., Boles, S., Wofsy, S., Berien, M., and Ojima, D., 2004a: Modeling gross primary production of temperate deciduous broadleaf forest using satellite images and climate data. Remote Sens. Environ., 91, 256-270.

Xiao, X. M., Hollinger, D., Aber, J., Goltz, M., Davidson, E. A., Zhang, Q. Y., and Moore, B., 2004b: Satellite-based modeling of gross primary production in an evergreen needleleaf forest. Remote Sens. Environ., 89, 519-534.

Zhang, X., Friedl, M. A., Schaaf, C. B., Strahler, A. H., Hodges, J. C. F., Gao, F., Reed, B. C., and Huete, A., 2003: Monitoring vegetation phenology using MODIS. Remote Sens. Environ., 84, 471-475.

Zhao, M. S., Heinsch, F. A., Nemani, R. R., and Running, S. W., 2005: Improvements of the MODIS terrestrial gross and net primary production global data set. Remote Sens. Environ., 95, 164-176.

Zhou, L. M., Tucker, C. J., Kaufmann, R. K., Slayback, D., Shabanov, N. V., and Myneni, R. B., 2001: Variations in northern vegetation activity inferred from satellite data of vegetation index during 1981 to 1999 . J. Geophys. Res.-Atmos., 106, 20069-20083. 